\title{
Failure of an under-dip shale slope and its response under excavation conditions
}

\author{
Bin Li*, Yanzhi Zhu, Fuzhou Qi and Zhenxia Yuan \\ School of Civil Engineering and Architecture, Zhongyuan University of Technology, Zhengzhou, 450007, China \\ *Corresponding Author: 15683086591@163.com
}

Submitted: 07/04/2019

Revised: $\quad 09 / 11 / 2020$

Accepted: 15/11/2020

\begin{abstract}
A landslide has occurred in the cut slope located in Chongqing Xi railway station. This slope belongs to a shale under-dip slope and has a complex failure mechanism. Some on-site investigations have been made to explore the deformation characteristics of this slope, and structural geology analyses and outcomes of geological investigations in situ are firstly described. The progressive failure process of the slope during unloading excavation has also been simulated by the Universal Distinct Element Code (UDEC). The obtained deformation characteristics of the slope have proven to well match the field measurements, which verifies the practicability of the UDEC model.
\end{abstract}

Keywords: landslide; under-dip slope; geological investigations; excavation; UDEC simulation.

\section{INTRODUCTION}

Recent work on failure mechanism has concentrated on buckling deformations on anaclinal slopes (Cavers, D.S., 1981; Pant, S.R. et al., 1999; Li, Q. et al., 1990; Liu, X.L. et al., 2002), where penetrative discontinuities are dipped into the slopes. However, Lugeon (1933) suggested that toppling deformation has also occurred on slopes, where penetrative discontinuities are dipped more steeply but in the same direction as the slope. Such slopes, in which the discontinuities are dipped under the slopes, are called under-dip slopes (Cruden, 1989). Some failures on underdip slopes were found in the Highwood Pass in Kananaskis Country, Alberta, Canada, by Tang (1986) and in the Yellowhead Pass by Cruden (1989). Cruden (1989) showed that, with the assumptions of Goodman and Bray (1976), toppling can occur on under-dip slopes without the assistance of external forces. Several researchers have conducted some studies on the failure mechanism of the under-dip stratified rock slope. Cruden et al. (1994) investigated the topples found by Tang (1986) and reported modes and discontinuities characteristic of topples on under-dip slopes, analyzed geological controls of toppling, and explained the processes of toppling on under-dip slopes. However, the deformation modes of slopes vary with geological structures, strength of rock blocks, and topography. These studies only concentrate on the overall toppling deformations of the under-dip slopes in some particular cases, which is not comprehensive, and it has been proved in some engineering examples that the failure mechanism and deformation characteristics of these under-dip slopes have been proven to be complex, which involve a series of processes such as sliding, buckling, and flexural toppling deformation (Li B. et al., 2020). Some researchers have studied the deepseated gravitational slope deformation on a shale dip-slope by different methods (Chigira M. et al., 2013; Hou Y.L. et al., 2014). However, there are few studies on the deformations of shale under-dip slope.

Numerical modeling techniques such as FEM, DEM, and NMM have been developed and applied for studying the complex failure of the rock slope (Pritchard and Savigny 1990, 1991; Alejano et al., 2010; Stead et al., 2006). Among 
the various numerical methods, the distinct element code UDEC has been widely used to investigate various rock slope failure mechanisms including those ranging from simple planar mechanisms to complex deep-seated toppling instability and buckling (Stead and Eberhardt, 1997).

Stress redistribution caused by excavation always induces the springback of rock mass in a certain depth of the slope, which may deteriorate the strength of rock mass and facilitate the development of slope movement (Li J.L. et al., 2003). Considering the lack of studies involving the complex deformation modes on shale under-dip slopes, based on the shale under-dip slope discovered in Chongqing Xi Railway Station, this paper first analyzes the deformation characteristics of the slope on the basis of geotechnical investigations performed on the in situ landslide with the consideration of geological structure, and then UDEC models are built to further explore the deformations of the slope under excavation conditions.

\section{GEOLOGY OF THE STUDY AREA AND FAILURE DESCRIPTION}

Chongqingxi Railway Station under construction is located in the Sha Pingba District of Chongqing. It is a traffic hub, which is based on railway and gathers passenger transport, bus, and light railway, which will be the biggest traffic hub in Chongqing after the construction is completed. The study area of this paper is the No. 6 slope, which ranges from $\mathrm{K} 1+080$ to $\mathrm{K} 1+470$ (Figure 1(b)) and is excavated on different steps, with each step being 10m high. It is a steep and high slope close to the railway station, which has a dip angle of more than $40^{\circ}$ and a total height of more than 70 meters. If a large landslide occurs, North Circulation Road (Figure 1(b) in the revised manuscript), a main access to the railway station, and the whole station will be buried. In addition, there are still several private houses on the slope crest. Therefore, stability of the study area is quite significant for the construction and operation of Chongqing Xi Railway station. The plan view of the study area (No. 6 slope) with a landslide area and several unstable areas marked is shown in Figure 1(b).

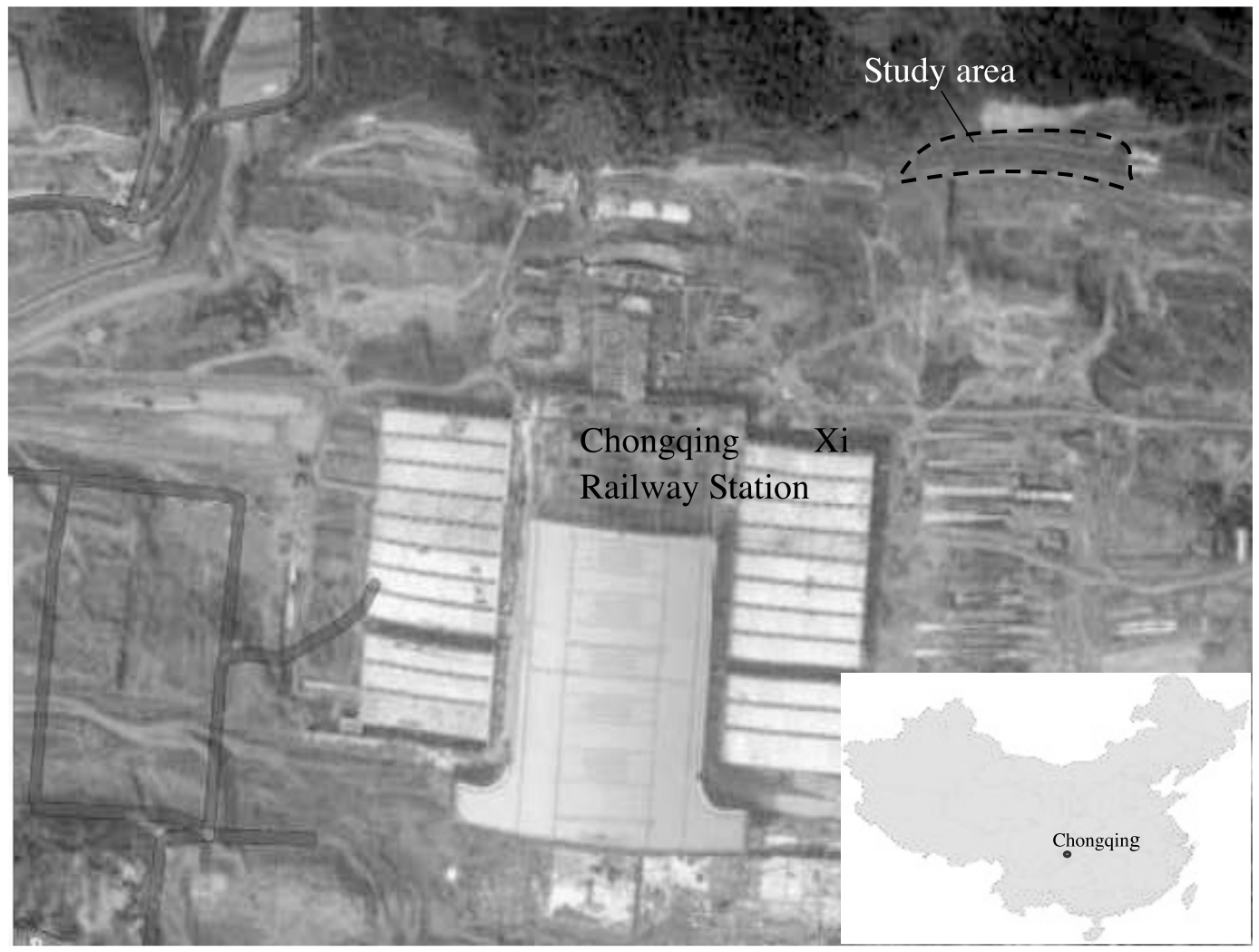

(a) 


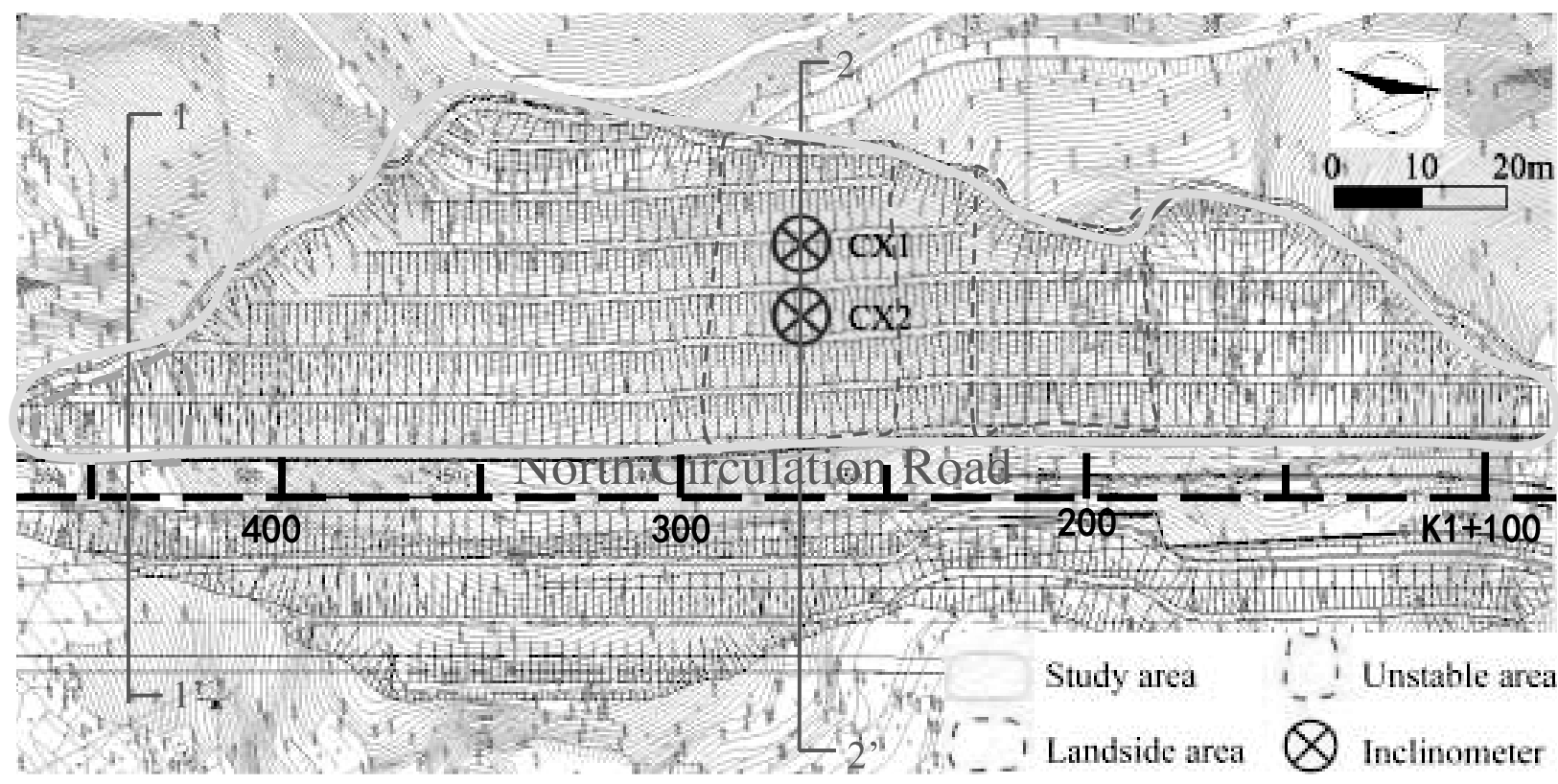

(b)

Figure 1. General view of the study area. (a) Satellite map of Chongqing Xi Railway Station (Chongqing, China); (b) plan view of the study area and boundaries of slope movement.

In the field surveys on the study area, cracking of slope face in the unstable areas shown in Figure 1(b) was observed as shown in Figure 2. The strike of the tensile cracks in the slope crest (Figure 2(a)-(e)) is almost consistent with that of slope face, and the crack openings are increasing with the intensifying of slope deformation. It can be seen that some cracks have been caulked to prevent rainfall permeation. The buckling of steel bars in the vegetation layer paved on the slope face (a slope protection technique called TBS) (Figure 2(h)) indicates that some settlement has occurred on the slope body. 


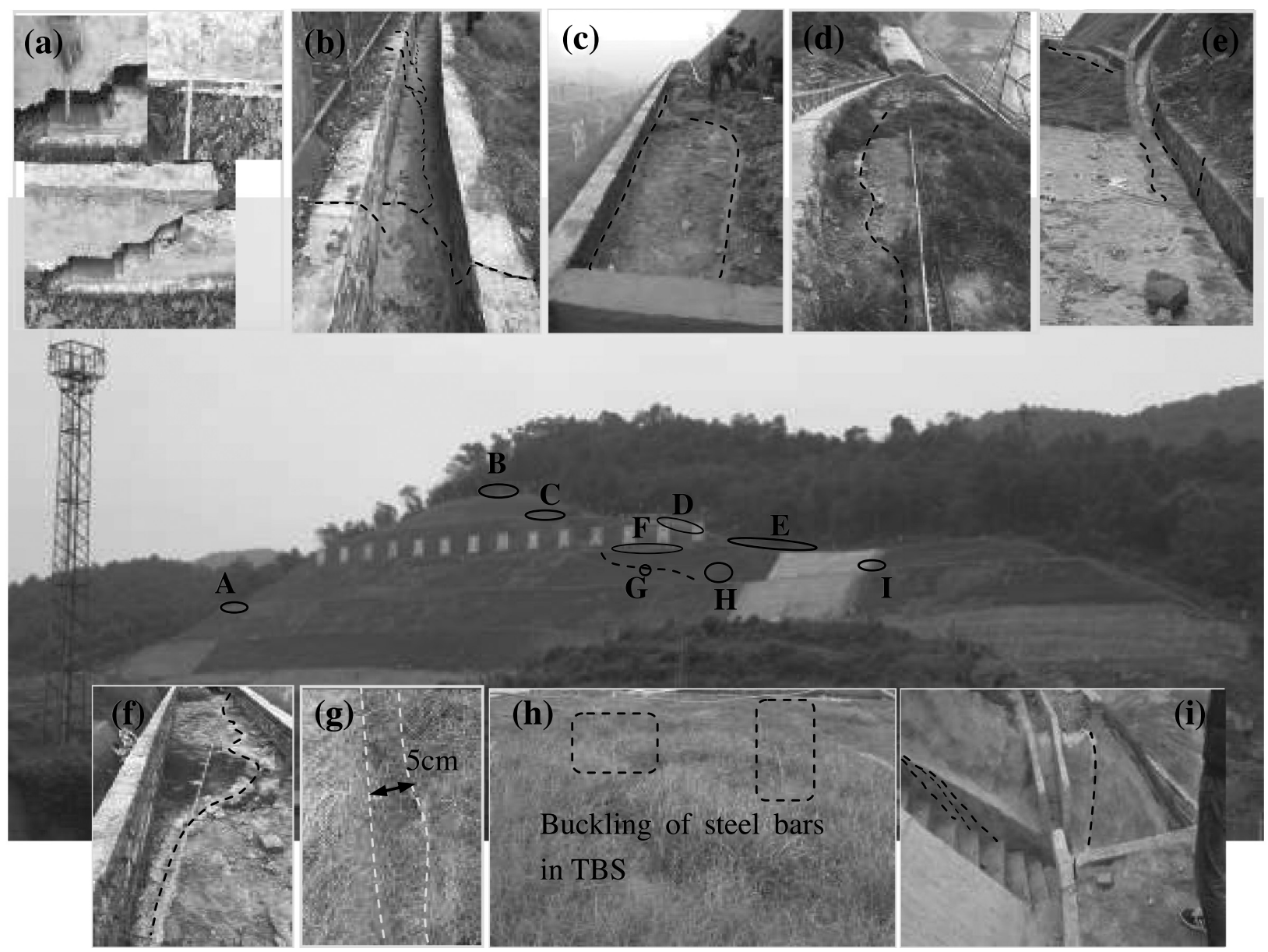

Figure 2. The complex slope deformation taking place in the study area. (a) to (e) Some tensile cracks at the slope crest corresponding to zone 'A-E'; (f) to (i) some observed cracks and deformation on the slope body corresponding to the zone 'F-I'.

The studied slope is an under-dip shale slope, and the bedding plane spacing is $0.2-0.4 \mathrm{~m}$. The length of sliding mass along slope strike is over $30 \mathrm{~m}$, the height is over $8 \mathrm{~m}$, and the rock mass is strongly and moderately weathered shale. Shale is a typical soft and fragile sedimentary rock, which is mainly comprised of clay mineral and always has obvious thin foliations called lamellation and the ease with which this rock splits along the direction of the lamellation weakens its resistance to erosion and weathering, which facilitates shale slopes to become prone to failure. There is no other unfavorable geology such as fault and debris flow in this field. Figure 3 shows the engineering geological section of the slope at cross section ' $1-1$ ' before failure. 


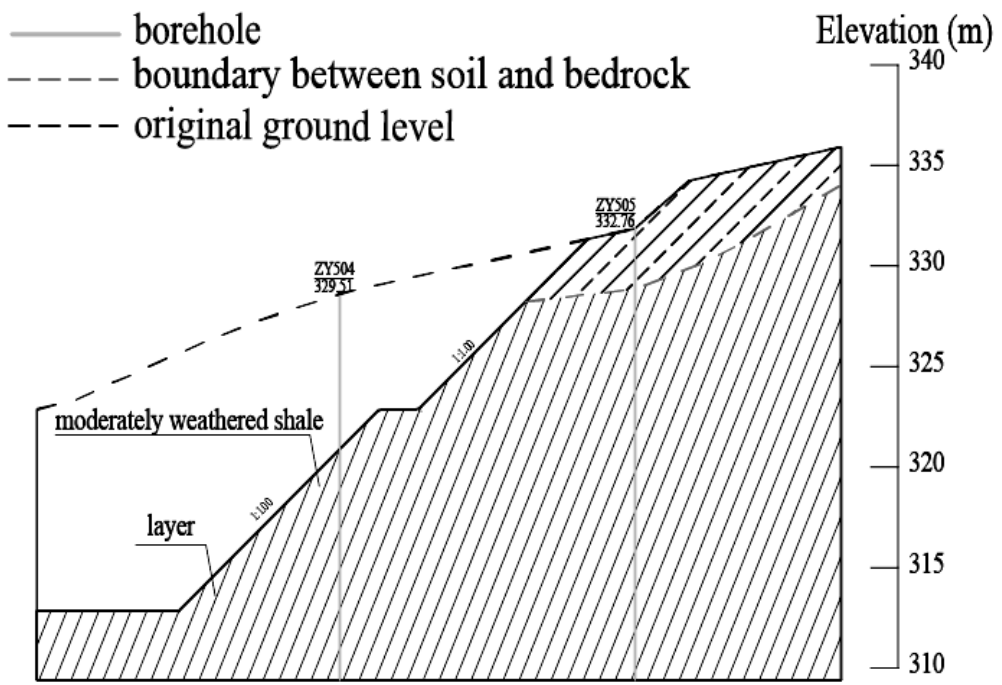

Figure 3. Engineering geological section of the slope at cross section ' $1-1$ '.

Figure 4 shows some deformation characteristics of the landslide area discovered from field surveys. In the upper part, as Figure 4(b) shows, we observed that the mechanical properties of the smooth and wet bedding plane in the trailing edge of the failure were rather poor and were present with an orientation of $102^{\circ} / 68^{\circ}$. According to the field measurement, the maximum depth of the sliding mass was $0.8 \mathrm{~m}$, and the sliding distance of rock mass in the upper sections of the slope along the bedding plane was about $1.0 \mathrm{~m}$. Layers at the toe become erect and have a maximum height of about $2 \mathrm{~m}$ and a thickness of about $0.2 \mathrm{~m}$ (Figure $4(\mathrm{a})$ ). This rotation of layers may be due to the pushing force from the damaged rock mass behind (Figure 4(c)). In addition, buckling of rock layers was also observed in the landslide area (Figure 4(d)).

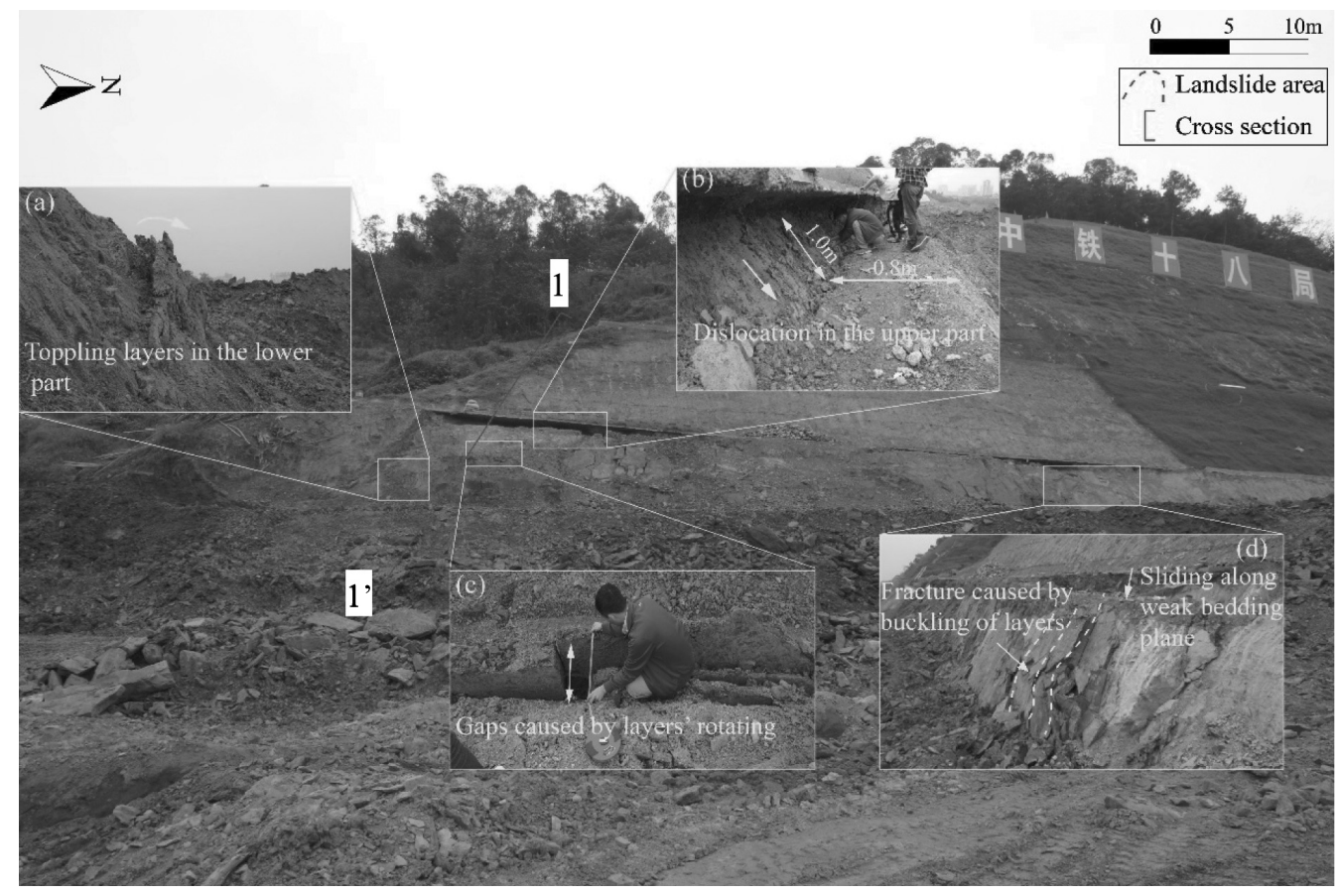

Figure 4. Panoramic view of the landslide area and some deformation characteristics from field surveys. 
Based on the structural characteristics of the damaged slope, it can be inferred that the failure process of the slope involves several stages including (1) slide-buckling deformation of the upper rock layers; (2) toppling deformation at the toe; (3) connection of fracture surfaces ( $\mathrm{Li} \mathrm{Bin,} \mathrm{et} \mathrm{al.,2020).}$

\section{SIMULATION ON EXCAVATION RESPONSE OF THE SLOPE}

To explore the deformation of the slope under effects of excavation, a numerical model at cross section ' $2-2$ ' as Figure 5 shows is built. The numerical model has a width of $120 \mathrm{~m}$ in horizontal direction and a height of $90 \mathrm{~m}$ in vertical direction, from the elevation of $20 \mathrm{~m}$ below the designed elevation of the first-step slope toe to the crest of the slope. The joint sets considered in the numerical model are listed as follows: bedding planes: an orientation (dip/dip direction) of $68^{\circ} / 102^{\circ}$, a spacing of $10-20 \mathrm{~cm}$, and a persistence of $8-10 \mathrm{~m}$; Joint set 1: an orientation (dip/dip direction) of $75^{\circ} / 295^{\circ}$, a spacing of $20 \mathrm{~cm}$, and a persistence of about $5 \mathrm{~m}$; Joint set 2 : an orientation (dip/dip direction) of $15^{\circ} / 270^{\circ}$, present in a range from the slope surface horizontally into the slope about $10 \mathrm{~m}$, with a spacing of $15 \mathrm{~cm}$, and a persistence of about $3 \mathrm{~m}$. The simulation is conducted with linearly elastic blocks and Coulomb-slip joint material model in UDEC.

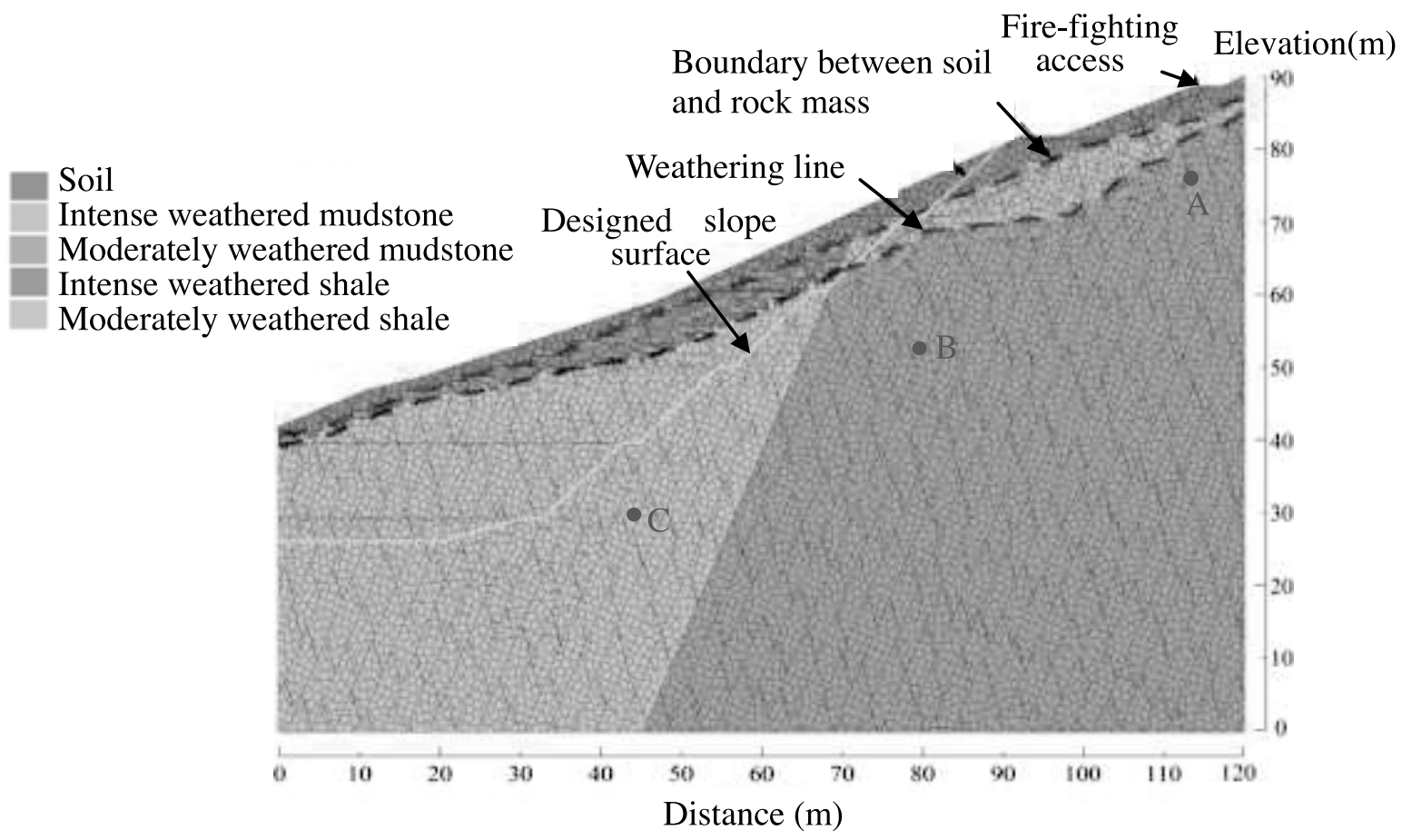

Figure 5. Slope model at cross section '2-2'. Point A, Point B, and Point C are displacement history points set for simulation.

The shear strength reduction technique (Dawson et al., 1999) was applied in this study to simulate the evolution of slope deformation under the excavation conditions. In order to obtain the microparameters of the contacts in the UDEC model, a series of confined compression tests based on UDEC models were performed to achieve consistency between the microproperties of the contacts and macroproperties of the rock mass by trial and error approaches. The details on this calibration process have been described in our previous research paper (Li Bin, et al. 2020). The ultimate input parameters for UDEC modelling are listed in Table 1. 
Table 1. UDEC input data for intact rock and contacts.

\begin{tabular}{|c|c|c|c|}
\hline Parameters & Rock block & Joints & Other contacts \\
\hline Density $\left(\mathrm{kg} / \mathrm{m}^{3}\right)$ & 2427 & - & - \\
\hline Modulus of elasticity $(\mathrm{GPa})$ & 2.3 & & \\
\hline Poisson's ratio & 0.32 & & 80 \\
\hline Normal stiffness $(\mathrm{GPa} / \mathrm{m})$ & - & 34.33 & 62 \\
\hline Shear stiffness $(\mathrm{GPa} / \mathrm{m})$ & - & 30 & 1.86 \\
\hline Cohesion $(\mathrm{MPa})$ & - & 0.023 & 37 \\
\hline Friction angle $\left({ }^{\circ}\right)$ & - & 15 & 0.65 \\
\hline Tensile strength $(\mathrm{MPa})$ & - & 0.03 & 86 \\
\hline
\end{tabular}

Figure 6 shows the deformation distribution when excavation reaches different stages. Figure 6(a) shows that when the excavation reaches the fifth-step slope, the parameters of rock mass in the damaged zone produced in the previous calculating step are reduced by a reduction factor of 1.05, and through the elastoplastic mechanical calculation, the result shows that rebounding deformations occur at the rock mass at the toe of the slope, and the displacement orientation is perpendicular to the slope surface and points outwards. In addition, sliding deformation occurs at the overburden along the direction of maximum principle stress, the value of which is 2-3mm, and shearing deformation of $3-4 \mathrm{~mm}$ occurs at the interface between the overburden and the rock mass. The maximum displacement of the slope occurs at the overburden close to the top, the soil has an obvious downward displacement along the interface between the soil and rock mass, and the value is about $4 \mathrm{~mm}$. When the third-step slope is excavated as Figure 6(b) shows, the strength of the rock mass in the damaged zone produced in the previous calculation step is reduced. The calculation results show that rebounding displacements at the superficial part of the slope are about $4 \mathrm{~mm}$, the range of slope suffering deformations in the upper part extends, the distance from the inner element to the slope surface is about $8 \mathrm{~m}$ (Figure 6(b)), and the deformations of the upper slope increase with the increasing height of empty face. The maximum displacement occurs at the top of the fifth-step slope, the value is about $18 \mathrm{~mm}$, and the greater deformation at this area may be caused by the sliding of the strongly weathered rock mass above. Figure 6(c) shows the deformation distribution of the slope when excavation reaches the second-step slope. When the second-step slope is excavated, the parameters of rock mass in the damaged zone produced in the previous calculation step are reduced by a reduction factor of 1.15 . Then, as the calculation result shows, the deformation of the slope increases, the maximum displacement occurs at the fifth-step slope, and the value increases to $30 \mathrm{~mm}$. Figure $6(\mathrm{~d})$ shows the deformation distribution of the slope when excavation reaches the last step of the slope. When excavation reaches the first-step slope, by reducing the strength of the rock mass in the damaged zone determined in previous calculation step by a reduction factor of 1.35 , the calculation result shows that the maximum deformation still occurs at the superficial area of the fifth-step slope, the value is about $50 \mathrm{~mm}$, and shearing displacement valuing of about $33 \mathrm{~mm}$ occurs at the fourth-step slope, which indicates that sliding-shearing failure may occur at these areas of the slope. 


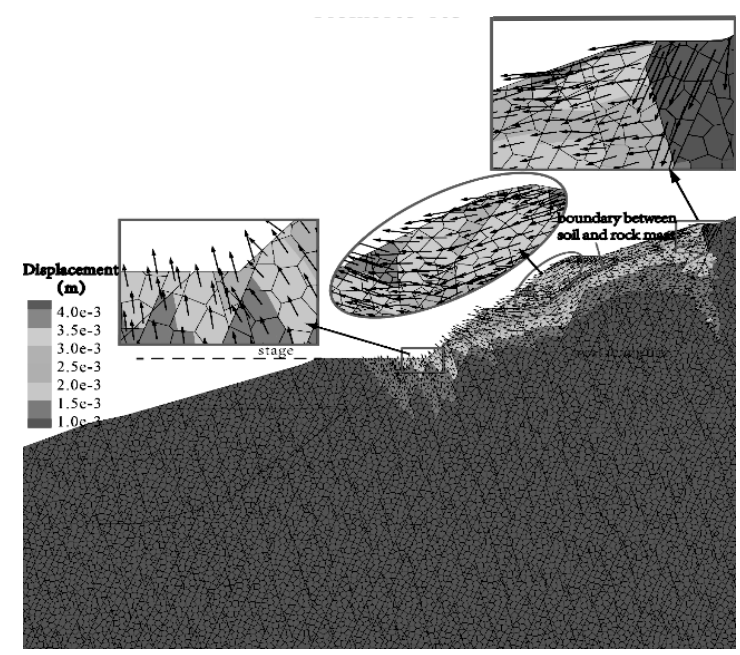

(a)

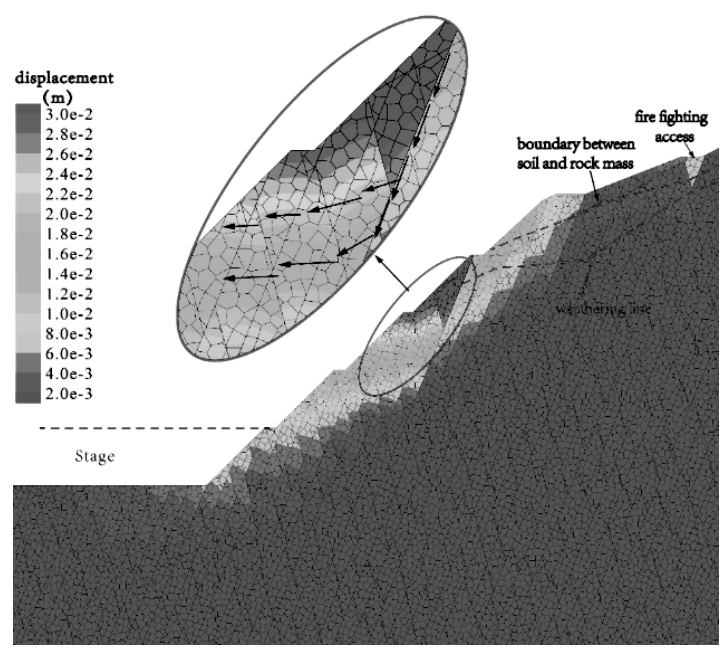

(c)

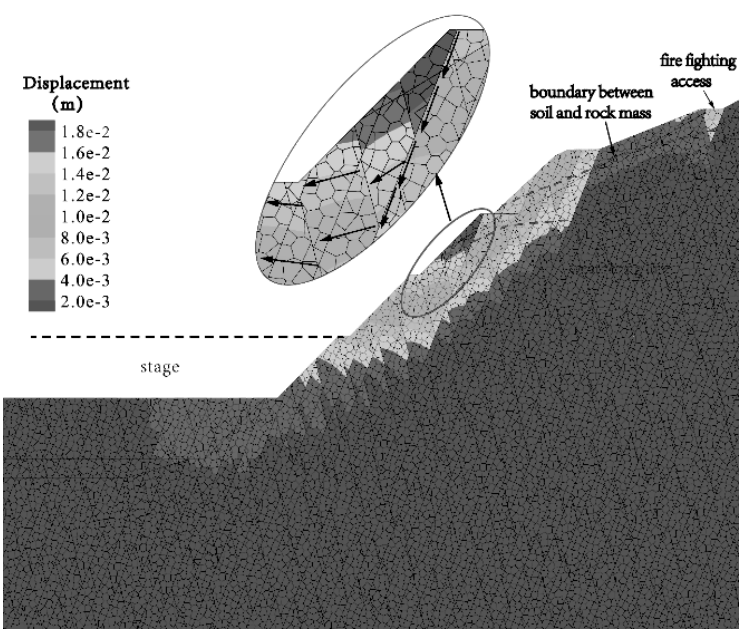

(b)

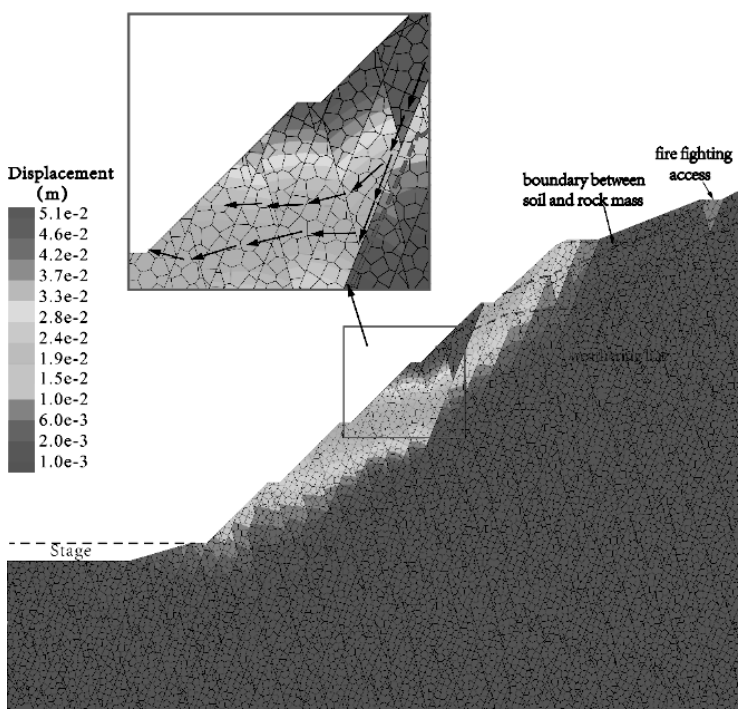

(d)

Figure 6. Slope deformation at different stages of excavation. (a) Stage I; (b) Stage II; (c) Stage III; (d) Stage IV.

\section{ON-SITE MONITORING RESULTS}

Figure 7 shows the displacement-depth curves obtained from the inclinometers in the boreholes CX1 and CX2 at the cross section '2-2'. In Figure 7(a), the peak value of horizontal displacement appears at the depth of $5 \mathrm{~m}$ in the borehole of CX1, which is rightly at the boundary between soil and rock mass. The displacement value decreases with the increasing depth, then at the depth larger than $22 \mathrm{~m}$, the displacement value becomes less than $2 \mathrm{~mm}$ and fluctuates in a minor scope, so it can be inferred that the influencing depth of the slope deformation is about $22 \mathrm{~m}$ at this location. In Figure 7(b), the monitoring results at CX2 show that the displacement value at the depth of $25 \mathrm{~m}$ is negative in 2016.12.13, while the value becomes positive abruptly after seven days, it may be caused by the disturbance of the monitoring hole. However, from the variation trend of horizontal displacement with depth, it can be inferred that there exist inflexions at the depth of $3 \mathrm{~m}$ and $13 \mathrm{~m}$, which indicates that the scope of the potential slip mass is probably at the depth of $3 \mathrm{~m}$ and $13 \mathrm{~m}$. 


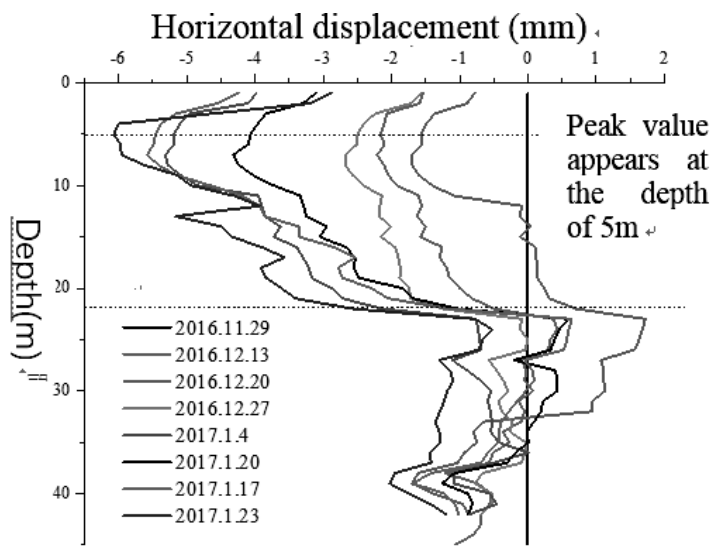

(a)

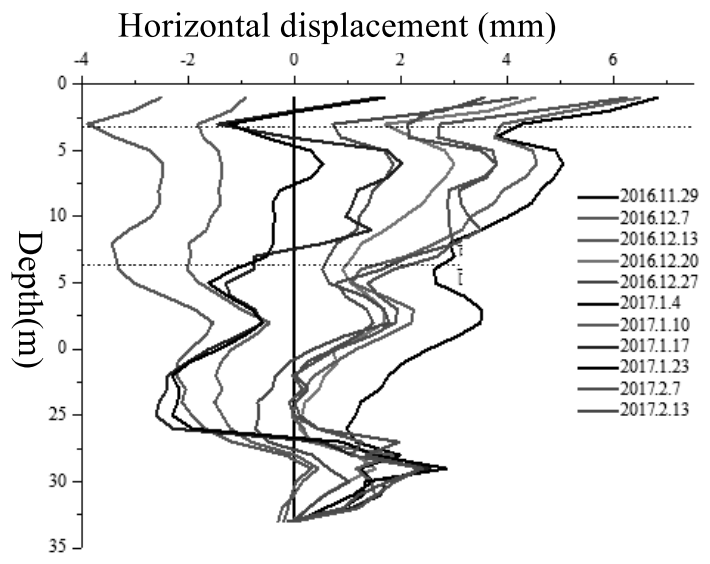

(b)

Figure 7. The measured displacement of monitoring holes at cross section '2-2'. (a) Monitoring hole CX1;

(b) monitoring hole CX2.

The comparison of displacements at points A, B, and C (Figure 5) after excavation between simulating and monitoring results is shown in Table 2. It shows that the simulation results agree well with the monitored results, which verifies the numerical model used in this study.

Table 2. Comparison between monitored and numerical displacements at monitoring points.

\begin{tabular}{|c|c|c|c|}
\hline & Point A & Point B & Point C \\
\hline $\begin{array}{c}\text { Monitored } \\
\text { displacement } \\
(\mathrm{mm})\end{array}$ & 6.1 & 6.2 & 4 \\
\hline $\begin{array}{c}\text { Simulating } \\
\text { displacement } \\
(\mathrm{mm})\end{array}$ & 5.2 & 7.0 & 4.5 \\
\hline Deviation & $14.7 \%$ & $12.9 \%$ & $12.5 \%$ \\
\hline
\end{tabular}

\section{CONCLUSION}

This study explored a failure of an under-dip slope comprised of shale through field investigation and numerical analysis. The deformation characteristics were firstly described. Subsequently, the universal distinct element code (UDEC) was applied for simulations to elucidate the deformation behavior of the under-dip slope caused by excavation. Finally, simulation results of the slope deformation were compared with the monitoring results from inclinometer measurements. Several conclusions can be summarized according to our study. Firstly, results of field surveys and simulation indicate that the inducing factors for the landslide can be summarized as follows: 1) the weakened bedding planes and water-degradation effects in the rear, which facilitate the sliding of rock mass in the upper part; 2) bedding planes with a steep dip angle larger than $60^{\circ}$ and a slope angle larger than $35^{\circ} ; 3$ ) thin-medium layered soft rock, commonly bed thickness. In addition, engineering activities such as excavation also weaken the strength of rock mass and facilitate the slope deformation. The depth of slope deformation region during excavation is about $8 \mathrm{~m}$, and the maximum displacement focuses on the fourth-fifth step of the slope, and the simulated displacements of the slope are in good agreement with the monitored results, which validates the use of UDEC models to describe the deformation evolution of a slope in a real construction environment. 


\section{ACKNOWLEDGMENT}

Data provided by the local engineering department have significantly strengthened the objectivity of the paper. Their assists are gratefully acknowledged.

\section{REFERENCES}

Alejano, L.R., Gómez-Márquez, I. \& Martínez-Alegría, R. 2010. Analysis of a complex toppling-circular slope failure. Engineering Geology. 114(1-2): 93-104.

Cavers, D.S. 1981. Simple methods to analyze buckling of rock slopes. Rock Mech. 14: 87-104.

Chigira, M., Hariyama, T. \& Yamasaki, S.2013. Development of deep-seated gravitational slope deformation on a shale dipslope: Observations from high-quality drill cores. Tectonophysics, 605: 104-113.

Cruden, D.M. 1989. The limits to common toppling. Canadian Geotechnical Journal, 26:737-742.

Cruden, D.M. \& Hu, X.Q. 1994. Topples on underdip slopes in the Highwood Pass, Alberta, Canada. Quarterly Journal of Engineering Geology, 27:57-68.

Dawson, E.M., Roth, W.H. \& Drescher, A. 1999. Slope stability analysis by strength reduction. Geotechnique, 49(6):835-840.

Goodman, R.E. \& Bray, J.W. 1976. Toppling of Rock Slopes, Proceedings, American Society of Civil Engineers, Specialty Conference, Rock Engineering for Foundations and Slopes, Vol.2,Boulder, Colorado, 201-234.

Hou,Y.L., Chigira, M. \& Tsou, C.Y. 2014. Numerical study on deep-seated gravitational slope deformation in a shale-dominated dip slope due to river incision. Engineering Geology, 179:59-75.

Li, Q. \& Zhang, Z.Q. 1990. Mechanism of buckling and creep-buckling failure of the bedded rock masses on the consequent slope. Journal of Chengdu College of Geology, 17(4):97-103.(in Chinese)

Liu, X.L., Zhou, D.P. 2002. Stability analysis of layered dip rocky slopes with elastic plane theory. Rock and Soil Mechanics, 23:162-165.

Li J.L. 2003. Unloading Rock Mass Mechanics. China Water \& Power Press.

Li, B., Huang, D. \& Zhu, Y.Z., 2020. A complex slide-buckling-toppling failure of under-dip soft rock slopes. European Journal of Environmental and Civil Engineering. DOI: 10.1080/19648189.2020.1839791.

Lugeon, M. 1933. Barrages et Geologie. Roche. Lausanne.

Pant, S.R. \& Adhikary, D.P. 1999. Implicit and explicit modelling of flexural buckling of foliated rock slopes. Rock Mechanics and Rock Engineering, 32(2):157-164.

Pritchard, M.A. \& Savigny, K.W. 1990. Numerical modelling of toppling. Canadian Geotechnical Journal, 27: 823-834.

Pritchard, M.A. \& Savigny, K.W. 1991. The Heather Hill landslide: an example of a large scale toppling failure in a natural slope. Canadian Geotechnical Journal, 28: 410-422.

Stead, D. \& Eberhardt, E. 1997. Developments in the analysis of footwall slopes in surface coal mining. Engineering Geology, 46:41-61.

Stead, D., Eberhardt, E. \& Coggan, J.S. 2006. Developments in the characterization of complex rock slope deformation and failure using numerical modelling techniques. Engineering Geology, 83: 217-235.

Tang, S.W.Y. 1986. Field examples of toppling induced by external forces, M.Eng. Report, University of Alberta, Edmonton, $62 p$. 